\title{
The HAT4 gene of Arabidopsis encodes a developmental regulator
}

\author{
Mark Schena, ${ }^{1}$ Alan M. Lloyd, and Ronald W. Davis \\ Department of Biochemistry, Beckman Center, Stanford University Medical Center, Stanford, California 94305-5307 USA
}

\begin{abstract}
The HAT4 gene from the plant Arabidopsis thaliana encodes a homeo domain protein that contains a leucine zipper motif. Homeo domain-leucine zipper (HD-Zip) proteins have not been found in animal systems, suggesting that HAT4 may define a new family of transcription factors that regulate higher plant development. To explore this possibility, functional studies of HAT4 were carried out in yeast and in transgenic plants. Point mutants of HAT4 isolated in yeast define functionally critical residues within the HD-Zip domain, many of which correspond to highly conserved positions in known homeo domains and leucine zippers. Transgenic plants bearing constructs that alter HAT4 expression exhibit a series of interesting developmental phenotypes, including changes in morphology and developmental rate. Thus, the HAT4 gene of Arabidopsis encodes an HD-Zip protein that functions as a novel developmental regulator.
\end{abstract}

[Key Words: HAT4; homeo box; leucine zipper; Arabidopsis; transcription factor]

Received October 28, 1992; revised version accepted December 22, 1992.

Certain regulatory genes encode proteins that regulate development (for reviews, see Hayashi and Scott 1990; Weintraub et al. 1991; Lewis 1992). In the case of genes that appear to function as master switches (Weintraub et al. 1991), ectopic expression of a given regulator can be sufficient to activate a complex developmental pathway such as the gratuitous formation of a specific cell or tissue type (for review, see McGinnis and Krumlauf 1992). One striking example comes from studies of muscle cell differentiation, in which constitutive expression of the myoD cDNA results in conversion of differentiated cell types such as fibroblasts into muscle cells (Davis et al. 1987). A second example derives from work on Drosophila neurogenesis. Ectopic expression of the singleminded gene can convert cells of the lateral central nervous system (CNS) into midline cells (Nambu et al. 1991). A third example is observed in gain-of-function Antennapedia mutations, in which the fly antenna is homeotically transformed into a leg (for reviews, see Gehring 1987; Kaufman et al. 1990). It is important to note that a large fraction of developmental regulatory genes in animal systems encode transcription factors /for reviews, see Hayashi and Scott 1990; Weintraub et al. 1991; McGinnis and Krumlauf 1992).

Though less is known about developmental regulation in higher plants, recent evidence indicates that transcription factors also play a central role in plant development. In flower development, for example, a family of transcription factors that contain a conserved DNA-binding motif known as the MADS box (Ma et al. 1991) are required. One floral regulatory protein, the product of the

\footnotetext{
${ }^{1}$ Corresponding author.
}

agamous gene, is involved in determining stamen and carpel development in Arabidopsis (Yanofsky et al. 1990). Development of another structure in Arabidopsis, the so-called trichomes or leaf hairs, involves two genetic loci termed GL1 and TTG (Koornneef 1981). The product of the GL1 gene, which is required to initiate the trichome developmental pathway, encodes a member of the Myb transcription factor family (Oppenheimer et al. 1991). In addition, a Myc homolog encoded by the maize $R$ locus (Ludwig et al. 1989) can functionally complement an Arabidopsis ttg mutant (Lloyd et al. 1992), indicating that the TTG locus probably encodes a transcription factor. In maize, mutations in the homeo box gene Knotted-1 cause alterations in leaf development (Vollbrecht et al. 1991).

In an attempt to identify new developmental regulatory genes in Arabidopsis, the isolation and characterization of homeo box genes was recently undertaken (Schena and Davis 1992). Two observations suggested a priori that the products of homeo box genes (i.e., homeo domain proteins) are good candidates for developmental regulators in Arabidopsis. First, considerable evidence indicates that mechanisms of transcriptional control have been highly conserved in eukaryotic organisms (for reviews, see Mitchell and Tiian 1989; Schena 1989; Struhl 1989; Ptashne and Gann 1990; Guarente and Bermingham-McDonogh 1992), including higher plants (Ma et al. 1988; Schena et al. 1991b; Katagiri and Chua 1992). Thus, the role of the homeo domain as a regulatory domain in animal systems (Gehring 1987; Scott et al. 1989; McGinnis and Krumlauf 1992), implied that this motif might also be found in developmental regulatory proteins from plants. Second, it has long been known that 
Arabidopsis morphology changes dramatically in response to specific external stimuli such as changes in light intensity (for review, see Okada and Shimura 1992), indicating that developmental responses of this type may involve linkage of the environment to development via the products of developmental control genes.

Presented here is an analysis of the homeo box gene HAT4 (homeo box from Arabidopsis thaliana), which encodes a member of the Arabidopsis homeo domain protein superfamily (Schena and Davis 1992). HAT4 was chosen for intensive analysis in part because it contains a novel 90-amino-acid segment termed the homeo domain-leucine zipper (HD-Zip) motif. HD-Zip proteins comprise a subfamily of homeo domain proteins in $\mathrm{Ar}$ abidopsis (Ruberti et al. 1991; Mattsson et al. 1992; Schena and Davis 1992) and have not yet been identified in animal systems. The apparent uniqueness of HD-Zip proteins to higher plants suggested that these factors might mediate novel developmental pathways in Arabidopsis, such as the coupling of development to the environment (Schena and Davis 1992).

Complementary approaches in yeast and transgenic plants were used to examine HAT4 function. In the yeast experiments a genetic selection was used to isolate point mutants of HAT4. The goal of the yeast experiments was to explore whether the HD-Zip domain contains a functional homeo domain and a leucine zipper, as sequence inspection suggests. The use of yeast to study transcription factors from higher plants is an extension of previous studies showing that basic mechanistic questions regarding mammalian transcription factor function are addressed more rapidly in yeast than in mammalian cells (Schena and Yamamoto 1988; Schena et al. 1989). In the second set of experiments, reverse genetics in whole plants was exploited to examine the developmental role of HAT4. The basic strategy of the transgenic plant experiments was to use a series of expression vectors to alter the levels of the HAT4 protein in vivo. It was reasoned that if HAT4 encodes a developmental regulator, reducing or elevating the levels of the protein should result in phenotypic changes.

\section{Results}

\section{Structure of the HAT4 gene}

To determine the structure of the HAT4 gene, genomic clones were isolated using the polymerase chain reaction (PCR). Sequence analysis of the isolated clones revealed the presence of three introns within the $1.35-\mathrm{kb}$ HAT4coding region, each bordered by nucleotides that closely conform to the AG/GT consensus for Arabidopsis splice sites (Fig. 1A). The overall structure of the HAT4 gene is such that the putative functional domains are located on separate exons; thus, helix 1 of the homeo domain resides on exon 2, helices 2 and 3 share exon 3 , and the leucine zipper maps to exon 4 (Fig. 1B).

\section{Yeast slow growth reversal assay}

Earlier studies revealed that a variety of eukaryotic
DNA-binding domains fused to acidic activation sequences are toxic in yeast (Schena 1990; Wilson et al. 1991; Berger et al. 1992). The toxicity of the chimeric proteins, which is manifested as a slow growth phenotype, requires both a functional DNA-binding domain and an intact acidic activation sequence. The slow growth phenotype probably results from binding of the chimeric protein to recognition sites fortuitously present in the yeast genome, followed by the sequestration of essential components of the general transcription apparatus via the acidic activation and DNA-binding domains (Gill and Ptashne 1988; Schena et al. 1989; Berger et al. 1992).

The dependency of slow growth on DNA binding suggested a new method for analyzing eukaryotic DNAbinding domains of unknown binding specificity, in which mutations that impair function are isolated simply by selecting mutants that reverse the slow growth phenotype in yeast. In this genetic scheme, each of the chimeric proteins also contains a DNA-binding domain from the bacterial LexA protein; thus, mutants that are selectively impaired in the function of the eukaryotic DNA-binding domain retain the capacity to bind to $\operatorname{lex} A$ DNA and are therefore capable of activating a reporter gene linked to a lexA operator. The presence of the LexA domain allows mutants of interest to be rapidly distinguished from those that are compromised in protein solubility or stability.

\section{Expression of HAT4 in yeast}

As a first step toward developing a yeast assay for HAT4 function, a 390-bp fragment of the HAT4 cDNA encompassing the HD-Zip domain was inserted between sequences encoding the DNA-binding domain of the bacterial LexA protein and the transcriptional activation domains of yeast GAL4 (Fig. 2A). This chimera was then cloned into a high-copy-number vector and expressed in yeast. High-level expression of the LexA-HAT4-GAL4 chimeric protein markedly inhibited the growth of yeast cells relative to those expressing the LexA-GAL4 protein (Fig. 3), indicating that the slow growth phenotype required HAT4 sequences.

\section{HAT4 mutants isolated in yeast}

To generate HAT4 point mutants, the 390-bp HAT4 segment was excised selectively from the LexA-HAT4 GAL4 molecule, randomly mutagenized using PCR, and reinserted into the expression plasmid. Plasmids were then introduced into Escherichia coli to yield $\sim 5 \times 10^{4}$ independent transformants (Fig. 2B). Plasmids encoding presumptive HAT4 mutants were cotransformed into yeast cells with a $\operatorname{lex} A$ reporter plasmid fused to the $\beta$-galactosidase ( $\beta$-gal) gene, and large yeast colonies (slow growth reversal mutants) were selected. The revertants were then secondarily screened for $\beta$-gal expression to distinguish mutants of interest from those impaired in solubility or integrity. Yeast clones that displayed high 


\section{$\mathbf{A}$}

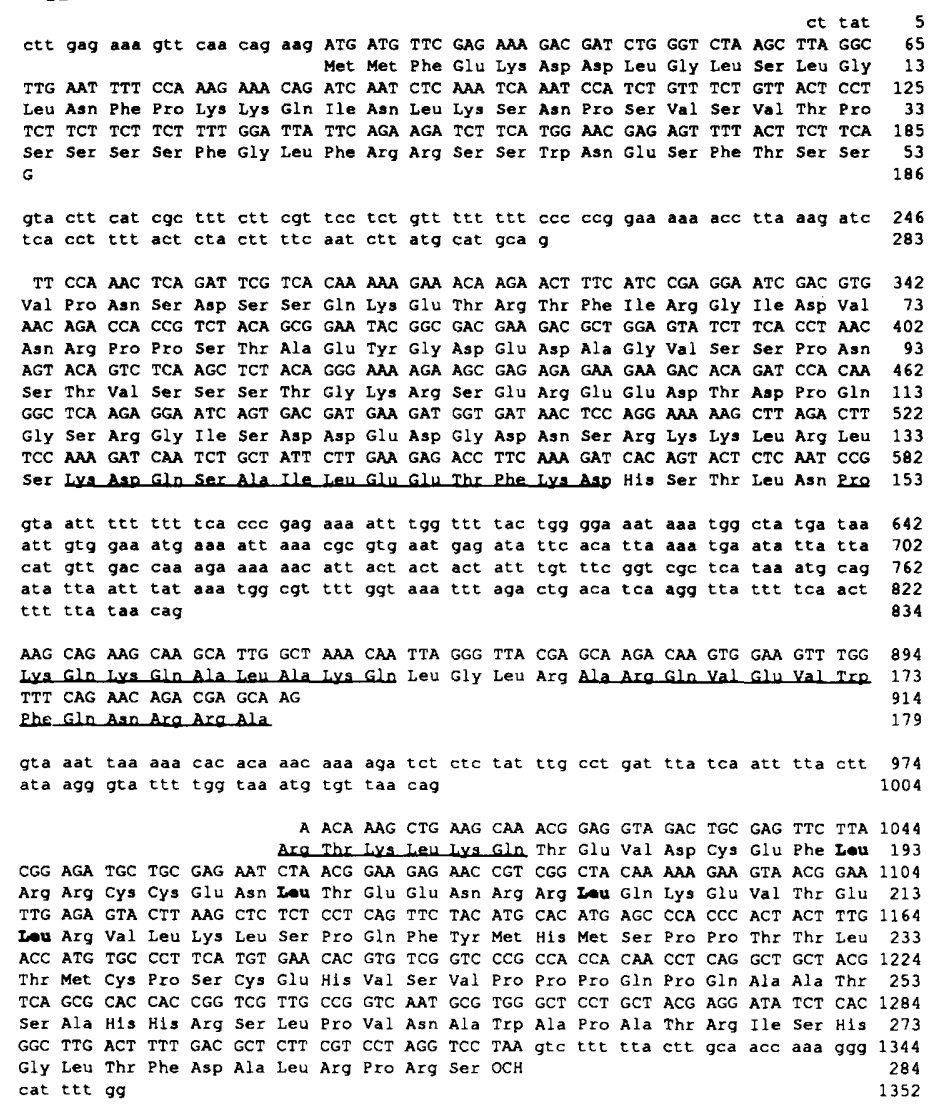
83

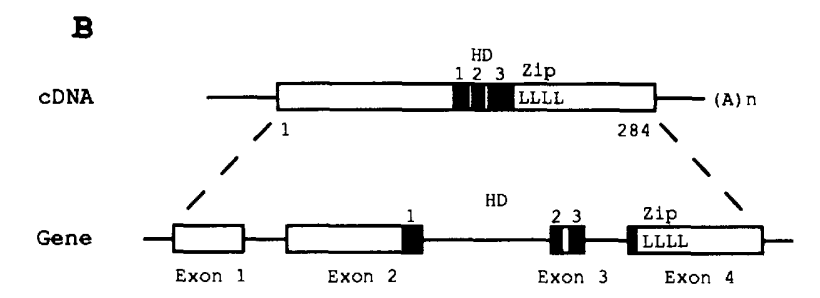

Figure 1. Structure of the HAT4 gene. $(A)$ Shown is the nucleotide sequence of the HAT4 gene and its conceptual translation. Exon sequences are shown in uppercase letters, and intron or untranslated sequences are shown in lowercase letters. Residues corresponding to the three putative $\alpha$-helices of the homeo domain are underlined, and the four heptadic leucines of the leucine zipper are shown in boldface type. Numbers in the margin tabulate nucleotides and amino acids, respectively. The sequence of the HAT4 gene has been submitted to GenBank/EMBL data bases under accession number Z19602. (B) Schematic illustration of the HAT4 cDNA and gene. The three presumptive homeo domain (HD) $\alpha$-helices and the heptadic leucines of the putative leucine zipper (Zip) are shown. Rectangular boxes and lines denote coding and noncoding sequences, respectively. $\beta$-gal activity (i.e., expressed intact LexA-HAT4-GAL4 proteins) were characterized further.

A total of 14 mutants that reversed the slow growth phenotype and retained lexA DNA-binding activity were isolated using the yeast assay, and in all cases the phenotypes segregated with the HAT4 segment. Sequence determination of the 14 inserts yielded 13 single mutants (Fig. 2C) and 1 double mutant (data not shown). Of the 13 single mutations, 12 mapped to the HAT4 homeo domain and 1 to the leucine zipper; notably, 11 of the 13 mutations mapped to residues that are highly conserved in bona fide homeo domains and leucine zippers (Fig. $2 \mathrm{C}$ ). The remaining two mutations mapped near conserved residues in homeo domain helix 1. $\beta$-Gal levels in cells containing the LexA-HAT4-GAL4 mutants were within twofold of the levels observed in yeast cells expressing the LexA-GAL4 protein (Table 1), indicating that the increased growth rate of the yeast cells was not attributable to decreased levels of the mutant proteins.

\section{Transforming whole plants with HAT4 expression constructs}

To investigate the role of the HAT4 in plant development, a series of expression vectors was constructed (Fig. 4). The vectors each contained the strongly constitutive $35 \mathrm{~S}$ promoter from the cauliflower mosaic virus fused to one of the following: the HAT4 cDNA in the antisense orientation (35S- $\alpha$ HAT4) to reduce the level of HAT4; the developmentally inert $\beta$-glucoronidase gene $135 \mathrm{~S}-$ GUS) as a wild-type control; or the HAT4 cDNA in the sense orientation (35S-HAT4) to elevate the level of HAT4 (Fig. 4). Transgenic lines transformed with these constructs were selected using kanamycin, and a total of 39 independent first generation (T1) lines were obtained. Seeds from the self-crossed $\mathrm{T} 1$ lines were collected, and second generation (T2) plants from 18 of the 39 lines were examined for phenotypic alterations.

\section{Altered HAT4 expression affects Arabidopsis development}

The presence of the expression constructs in the T2 lines was confirmed using PCR. Of the $18 \mathrm{~T} 2$ lines examined, 16 exhibited $3: 1$ segregation of the kanamycin resistance marker, indicating that all but 2 of the original $\mathrm{T} 1$ lines had acquired copies of the transgene at a single genomic locus (Table 2). Examination of the T2 seedlings revealed interesting developmental phenotypes in nearly all of the transgenic lines. Kanamycin-resistant seedlings of two of the six 35S- $\alpha$ HAT4 lines had shorter hypocotyls (portion of the stem connecting the first two leaves to the roots), larger and more numerous leaves, and a thicker root mass than the wild-type (35S-GUS) controls (Table 2; Fig. 5). Seedlings expressing the 35S-HAT4 construct exhibited roughly reciprocal phenotypes com- 

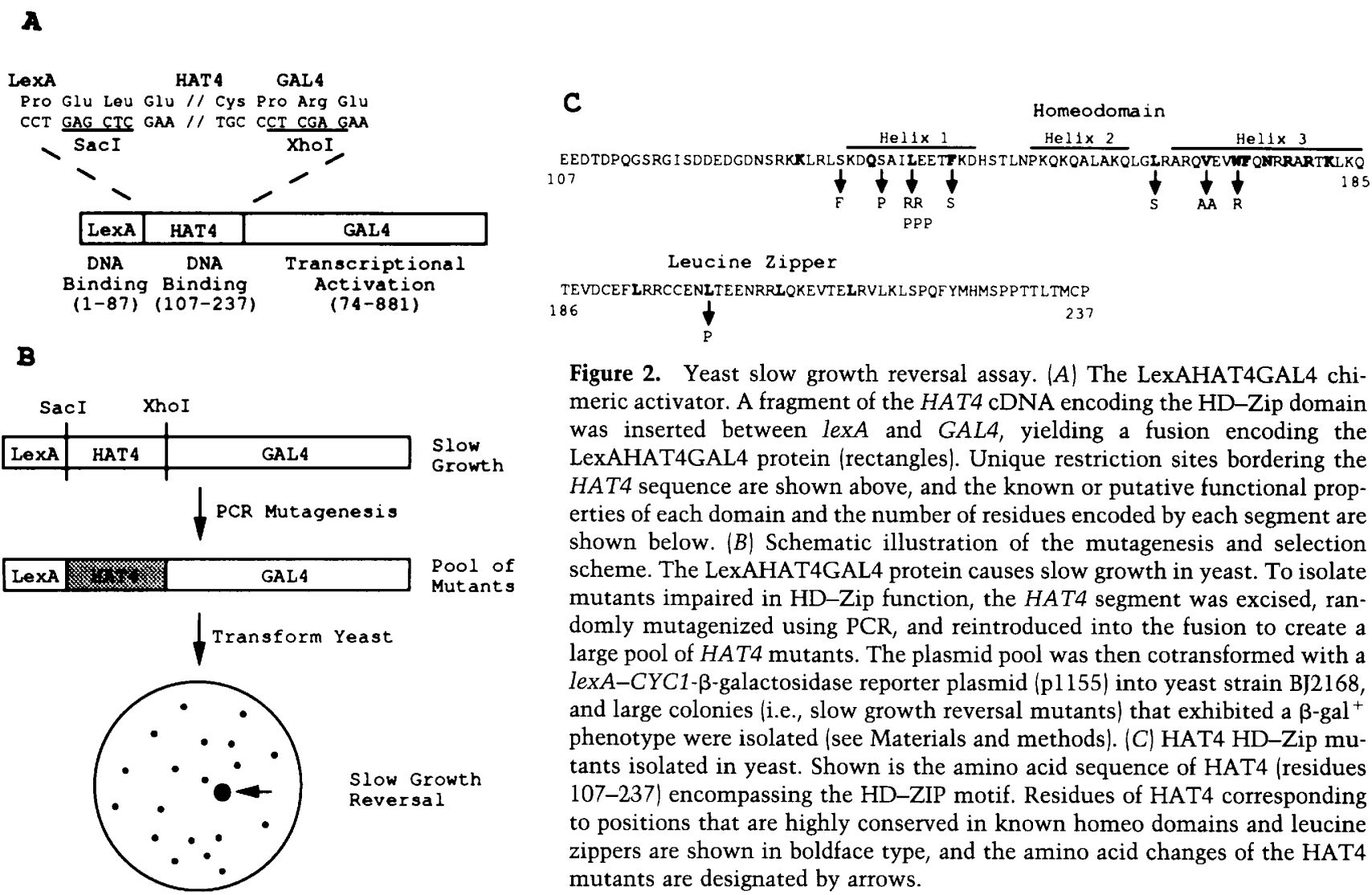

Figure 2. Yeast slow growth reversal assay. $(A)$ The LexAHAT4GAL4 chimeric activator. A fragment of the HAT4 cDNA encoding the HD-Zip domain was inserted between $\operatorname{lex} A$ and $G A L 4$, yielding a fusion encoding the LexAHAT4GAL4 protein (rectangles). Unique restriction sites bordering the HAT4 sequence are shown above, and the known or putative functional properties of each domain and the number of residues encoded by each segment are shown below. $(B)$ Schematic illustration of the mutagenesis and selection scheme. The LexAHAT4GAL4 protein causes slow growth in yeast. To isolate mutants impaired in HD-Zip function, the HAT4 segment was excised, randomly mutagenized using PCR, and reintroduced into the fusion to create a large pool of HAT4 mutants. The plasmid pool was then cotransformed with a lexA-CYC1- $\beta$-galactosidase reporter plasmid ( $\mathrm{p} 1155$ ) into yeast strain $\mathrm{BJ} 2168$, and large colonies (i.e., slow growth reversal mutants) that exhibited a $\beta$-gal ${ }^{+}$ phenotype were isolated (see Materials and methods). (C) HAT4 HD-Zip mutants isolated in yeast. Shown is the amino acid sequence of HAT4 (residues 107-237) encompassing the HD-ZIP motif. Residues of HAT4 corresponding to positions that are highly conserved in known homeo domains and leucine zippers are shown in boldface type, and the amino acid changes of the HAT4 mutants are designated by arrows.

pared with the lines expressing the antisense construct. Kanamycin-resistant seedlings of all nine 35S-HAT4 lines had longer hypocotyls, smaller and fewer leaves, a thinner root mass, and a darker green color than wildtype (35S-GUS) controls (Table 2; Fig. 5).

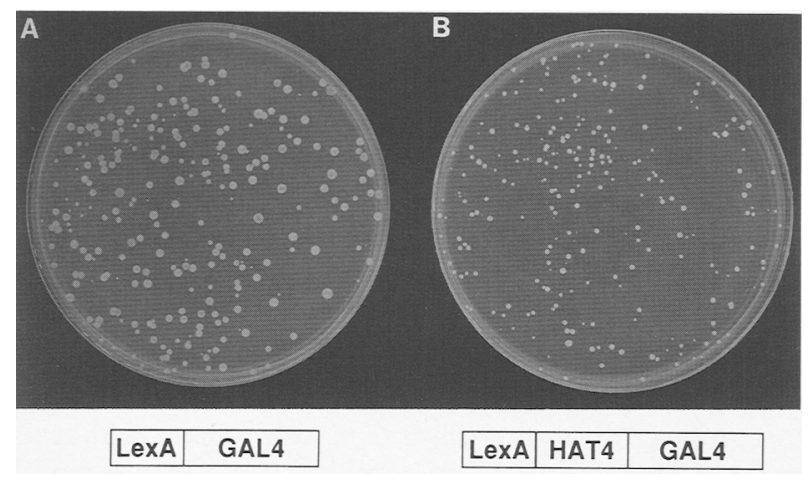

Figure 3. Expression of the LexAHAT4GAL4 protein in yeast. Yeast cells (BJ2168) transformed with a plasmid (pGLexAHAT4GAL4) expressing LexAHAT4GAL4 (B) grow more slowly than the same strain transformed with a plasmid ( $\mathrm{pG}$ LexAGAL4) expressing LexAGAL4 (A). Both of the expression plasmids are based on pG-1 (Schena et al. 1991a) and thus also contain the glycerol-3-phosphate dehydrogenase (GPD) promoter, the 3-phosphoglycerate kinase (PGK) transcription terminator, the yeast TRP1 gene, the yeast $2 \mu$ origin of replication, and the bacterial origin of replication and ampicillin resistance gene from pUC18.
The phenotypes of adult $\mathrm{T} 2$ plants were similar to seedlings but more exaggerated (Fig. 6). As a result of HAT4-dependent changes in morphology and developmental rate, the formation of the first siliques (seed pods) was retarded by $\sim 10 \%$ in $35 \mathrm{~S}-\alpha \mathrm{HAT}$ plants and accelerated by approximately twofold in 35S-HAT4 plants relative to the wild type (Table 2; Fig. 6). Seed production from 35S-HAT4 plants was routinely 25 -fold greater than from wild-type plants of the same age (Fig. 6).

\section{Developmental phenotypes correlate with HAT4 gene dosage and transcript levels}

Third-generation (T3) seedlings derived from self-crossed T2 plants exhibited $3: 1$ or $1: 0$ segregation of kanamycin resistance, as expected for a dominant marker (Table 3). The phenotype of $\mathrm{T} 3$ seedlings homozygous for the 35S-HAT4 transgene was markedly more severe than in the heterozygous $\mathrm{T} 3$ seedlings derived from the same parent line (Fig. 7). Crosses of T2 plants homozygous or heterozygous for a given $35 \mathrm{~S}$ marker to wild-type plants yielded progeny that segregated kanamycin resistance $1: 0$ and $1: 1$, respectively. The altered developmental phenotypes segregated exclusively with the kanamycin marker in $>100$ seedlings examined from representative lines (data not shown).

The levels of the HAT4 transcript were assessed in both wild-type plants and in representative transgenic lines by Northern analysis. HAT4 expression in wild- 
Table 1. Point mutants of HAT4

\begin{tabular}{|c|c|c|c|c|}
\hline Plasmid & Insert & Codon change & Residue change & $\beta-G a l$ \\
\hline pG-1 & None & N.A. & N.A. & 3 \\
\hline pG-LexAGAL4 & LexA-GAL4 & N.A. & N.A. & 3781 \\
\hline pG-LexAHAT4GAL4 & LexA-HAT4-GAL4 & wild type & wild type & N.D. \\
\hline $\mathrm{pG}-\mathrm{T} 3$ & LexA-HAT4-GAL4 & $\mathrm{TCC}>\mathrm{TTC}$ & Ser134 > Phe & 2048 \\
\hline pG-T51 & LexA-HAT4-GAL4 & $\mathrm{TCT}>\mathrm{CCT}$ & Ser138 > Pro & 2363 \\
\hline $\mathrm{pG}-\mathrm{T} 6$ & LexA-HAT4-GAL4 & $\mathrm{CTT}>\mathrm{CGT}$ & Leu $141>$ Arg & 2166 \\
\hline $\mathrm{pG}-\mathrm{T} 15$ & LexA-HAT4-GAL4 & $\mathrm{CTT}>\mathrm{CGT}$ & Leul41 > Arg & 2159 \\
\hline pG-M25 & LexA-HAT4-GAL4 & $\mathrm{CTT}>\mathrm{CCT}$ & Leu $141>$ Pro & 2740 \\
\hline $\mathrm{pG}-\mathrm{T} 28$ & LexA-HAT4-GAL4 & $\mathrm{CTT}>\mathrm{CCT}$ & Leu141 > Pro & 2721 \\
\hline pG-T52 & LexA-HAT4-GAL4 & $\mathrm{CTT}>\mathrm{CCT}$ & Leu $141>$ Pro & 2461 \\
\hline pG-T72 & LexA-HAT4-GAL4 & $\mathrm{TTC}>\mathrm{TCC}$ & Phe145 > Ser & 1912 \\
\hline pG-M14 & LexA-HAT4-GAL4 & TTA $>$ TCA & Leul65 > Ser & 1930 \\
\hline $\mathrm{pG}-\mathrm{M} 7$ & LexA-HAT4-GAL4 & GTG $>$ GCG & Vall $70>$ Ala & 1835 \\
\hline $\mathrm{pG}-\mathrm{M} 78$ & LexA-HAT4-GAL4 & GTG $>$ GCG & Vall $70>$ Ala & 1582 \\
\hline pG-M15 & LexA-HAT4-GAL4 & $\mathrm{TGG}>\mathrm{CGG}$ & $\operatorname{Trpl} 73>\operatorname{Arg}$ & 1950 \\
\hline $\mathrm{pG}-\mathrm{T} 4$ & LexA-HAT4-GAL4 & $\mathrm{CTA}>\mathrm{CCA}$ & Leu200 > Pro & 1673 \\
\hline
\end{tabular}

Yeast pG-1-based expression plasmids encode LexAHAT4GAL4 mutants that contain single-amino-acid changes in the HAT4 HDZip domain (see Fig. 2C). To confirm the integrity of the LexAHAT4GAL4 mutants, expression plasmids were cotransformed with a lexA-CYC1- $\beta$-gal reporter plasmid $(\mathrm{pl} 155)$ into yeast strain $\mathrm{BJ} 2168$, and transformants were assayed for $\beta$-gal activity (see Materials and methods). $\beta$-Gal values correspond to the average of triplicate measurements, which varied by $<20 \%$ and were consistent from day to day. (N.A.) Not applicable; (N.D.) not determined.

type plants was observed during all stages of development and in all tissues examined, although transcript levels were considerably higher in stems and leaves than in flowers (Fig. 8). Examination of the transgenic lines revealed the expected changes in HAT4 expression; namely, plants expressing the 35S- $\alpha$ HAT4 construct had $\sim 10$-fold lower levels of the HAT4 transcript relative to lines harboring the 35S-GUS construct, whereas those expressing the 35S-HAT4 construct possessed $\sim 10$-fold elevated levels of HAT4 mRNA (Fig. 8).

\section{Potential role of light in HAT4 function}

Arabidopsis morphology adapts profoundly to environ-

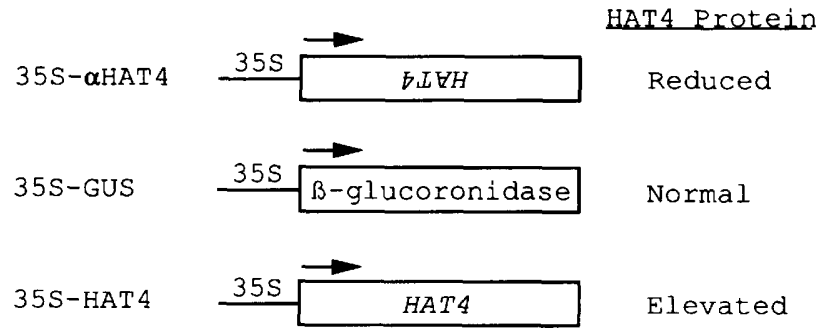

Figure 4. Vectors for altering HAT4 expression in transgenic plants. The intact HAT4 cDNA in the antisense orientation, the $\beta$-glucoronidase (GUS) gene, or the HAT4 cDNA in the sense orientation were inserted downstream of the strongly constitutive $35 \mathrm{~S}$ promoter from the cauliflower mosaic virus to yield expression vectors $35 \mathrm{~S}-\alpha \mathrm{HAT} 4,35 \mathrm{~S}-\mathrm{GUS}$, and 35S-HAT4, respectively. Plants expressing these constructs are predicted to have the designated HAT4 protein levels. All plasmids are pBI121 (Clontech) derivatives and thus also contain a transcriptional terminator from the nopaline synthase gene situated $3^{\prime}$ of the inserted cDNAs, an RK2 bacterial origin of replication, and a kanamycin resistance gene for selection in bacteria and Arabidopsis. mental stimuli such as changes in light intensity (Fig. 9), suggesting that developmental regulators may play a role in these adaptive responses. To investigate whether any of the transgenic lines with altered HAT4 expression possess altered light responses, seeds from various transgenic lines were grown in absolute darkness and analyzed for phenotypic alterations. The 35S- $\alpha$ HAT4 seeds germinated normally, giving rise to seedlings that exhibited an etiolated morphology (white, highly elongated, leafless developmental profile) characteristic of wildtype dark-grown plants; in contrast, $>50 \%$ of the seeds from three independent 35S-HAT4 lines were totally defective in germination (Fig. 10). The germination defect of 35S-HAT4 seeds was light reversible; interestingly, dark treatment of seeds that overproduce HAT4 yielded plants that were much larger than those derived from untreated seeds, suggesting that darkness and HAT4 overproduction may act in a synergistic manner to promote plant growth in the light (Fig. 11).

\section{Discussion}

It is interesting that the putative functional domains of HAT4 reside on separate exons. Such a configuration is consistent with the evolutionary model of exon shuffling (Dorit et al. 1990), which would postulate that the HAT4 gene was assembled during evolution from smaller functional units encoding individual $\alpha$-helices of the homeo domain (exons 2 and 3 ) and the leucine zipper coiled coil (exon 4). No compelling information derives from conceptual translation of the first exon of HAT4, although exon 1 may encode a transcriptional regulatory domain.

Several lines of genetic evidence suggest that HAT4 contains a functional HD-Zip domain. First, all of the mutants isolated using the yeast assay map to the 90 amino-acid (270-bp) HD-Zip domain, despite the fact 
Schena et al.

Table 2. Analysis of second-generation (T2) transgenic Arabidopsis lines

\begin{tabular}{|c|c|c|c|c|c|c|}
\hline T1 line & Vector & Background & $\begin{array}{l}\mathrm{T} 2 \\
\operatorname{Kan}^{\mathrm{R}} / \mathrm{Kan}^{\mathrm{S}}\end{array}$ & $\begin{array}{l}\text { T2 } \\
\text { hypocotyl (mm) }\end{array}$ & $\begin{array}{l}\mathrm{T} 2 \\
\text { silique (days) }\end{array}$ & $\begin{array}{l}\text { T2 } \\
\text { phenotype }\end{array}$ \\
\hline 1429 & $35 \mathrm{~S}-\alpha \mathrm{HAT} 4$ & Col-O & $60: 24$ & $1.8 \pm 0.2$ & $34 \pm 2.7$ & short \\
\hline 1431 & $35 \mathrm{~S}-\alpha \mathrm{HAT} 4$ & Col-O & $65: 20$ & $1.9 \pm 0.3$ & $35 \pm 1.9$ & short \\
\hline 1478 & $35 \mathrm{~S}-\alpha \mathrm{HAT} 4$ & RLD-O & $60: 21$ & $2.7 \pm 0.5$ & $39 \pm 2.7$ & normal \\
\hline 1479 & $35 \mathrm{~S}-\alpha \mathrm{HAT} 4$ & RLD-O & $69: 24$ & $2.7 \pm 0.4$ & $41 \pm 2.3$ & normal \\
\hline 1481 & $35 \mathrm{~S}-\alpha \mathrm{HAT} 4$ & RLD-O & $59: 19$ & $2.6 \pm 0.4$ & $38 \pm 1.7$ & normal \\
\hline 1482 & $35 \mathrm{~S}-\alpha \mathrm{HAT} 4$ & RLD-O & $74: 5$ & $2.9 \pm 0.4$ & $42 \pm 2.0$ & normal \\
\hline 1419 & 35S-GUS & RLD-O & $71: 7$ & $2.6 \pm 0.3$ & $40 \pm 2.1$ & normal \\
\hline 1420 & 35S-GUS & RLD-O & $64: 23$ & $2.5 \pm 0.5$ & $42 \pm 1.8$ & normal \\
\hline 1421 & 35S-GUS & Col-O & $61: 16$ & $2.4 \pm 0.3$ & $30 \pm 1.2$ & normal \\
\hline 1525 & 35S-GUS & Col-O & $51: 14$ & $2.5 \pm 0.4$ & $29 \pm 1.3$ & normal \\
\hline 1423 & 35S-HAT4 & RLD-O & $57: 16$ & $4.2 \pm 1.1$ & $23 \pm 1.2$ & tall \\
\hline 1425 & 35S-HAT4 & Col-O & $73: 21$ & $6.7 \pm 0.4$ & $16 \pm 2.3$ & tall \\
\hline 1426 & 35S-HAT4 & Col-O & $62: 22$ & $6.7 \pm 0.4$ & $16 \pm 1.9$ & tall \\
\hline 1427 & 35S-HAT4 & Col-O & $73: 20$ & $6.9 \pm 0.4$ & $17 \pm 1.6$ & tall \\
\hline 1468 & 35S-HAT4 & RLD-O & $96: 35$ & $3.5 \pm 0.8$ & N.D. & tall \\
\hline 1469 & 35S-HAT4 & RLD-O & $28: 11$ & $3.6 \pm 1.1$ & N.D. & tall \\
\hline 1471 & 35S-HAT4 & RLD-O & $97: 33$ & $4.9 \pm 0.6$ & $24 \pm 1.4$ & tall \\
\hline 1472 & 35S-HAT4 & RLD-O & $121: 42$ & $5.7 \pm 0.8$ & $22 \pm 2.5$ & tall \\
\hline 1474 & 35S-HAT4 & Col-O & $55: 27$ & $6.5 \pm 0.9$ & N.D. & tall \\
\hline
\end{tabular}

Columbia (Col-O) or RLD (RLD-O) Arabidopsis roots were transformed with the designated expession vectors and regenerated into first-generation (T1) plants. Seeds from self-crossed T1 plants were collected, plated on agar, and grown under bright light for 10 days. These second-generation (T2) seedlings were then scored for resistance $\left(\operatorname{Kan}^{\mathrm{R}}\right)$ or sensitivity $\left(\mathrm{Kan}^{\mathrm{S}}\right)$ to kanamycin, and hypocotyls from 20 representative kanamycin-resistant seedlings were measured and recorded as standard deviations of the mean. Ten representative 7-day-old kanamycin-resistant seedlings from the same plates were also transferred to soil, and the appearance of the first seed pod (silique) on each plant was recorded and calculated as a standard deviation of the mean. The developmental phenotypes and additional experimental details are described in Results and Materials and methods, respectively. (N.D.) Not determined.

that a 390-bp segment of the HAT4 cDNA was mutated. Second, 10 of the 12 homeo domain mutations within the 90-amino-acid domain map specifically to residues that are highly conserved in known homeo domains (Scott et al. 1989; Gehring et al. 1990); furthermore, the leucine zipper mutation (Leu200Pro) occurs at a position shown in GCN4 to be sensitive to proline substitution (Hu et al. 1990). The preponderance of mutations in the homeo domain relative to the leucine zipper is consistent with the compact structural configuration of the homeo domain (Kissinger et al. 1990; Wolberger et al. 1991) relative to the extended conformation of the coiled coil (O'Shea et al. 1989, 1991). The two remaining mutations (Ser134Phe and Ser138Pro) both map to homeo domain helix 1 and may impair HD-Zip function by disrupting the packing or folding of the $\alpha$-helix.

Figure 5. Effect of altered HAT4 expression on Arabidopsis seedling development. Seeds were plated on agar and grown for 10 days under bright light (see Materials and methods). Representative seedlings were chosen for the photographs and correspond to progeny of the following $\mathrm{T} 1$ lines (Table 2): (A) 35S- $\alpha$ HAT4 line 1429, (B) 35S-GUS line 1421, and (C) 35S-HAT4 line 1427. Shown below each photograph is the presumptive HAT4 protein level in each seedling.

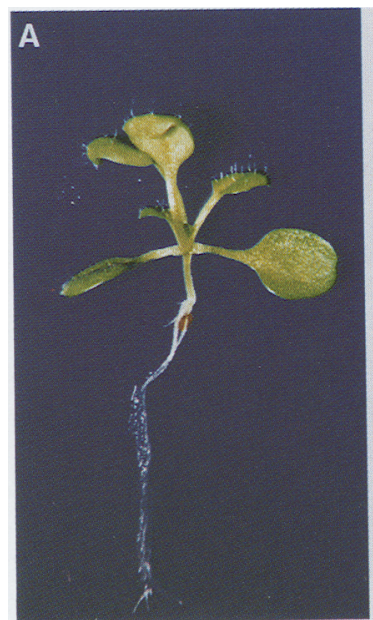

Reduced HAT4

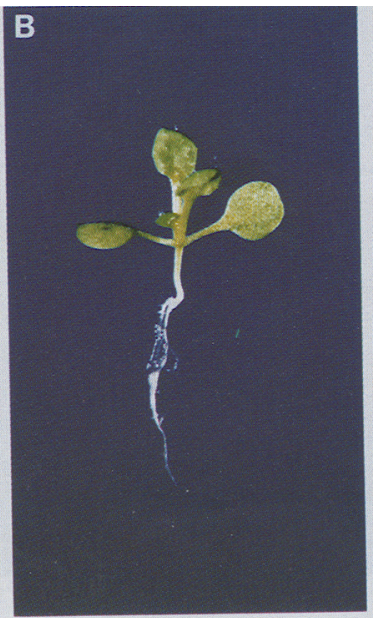

Wild type

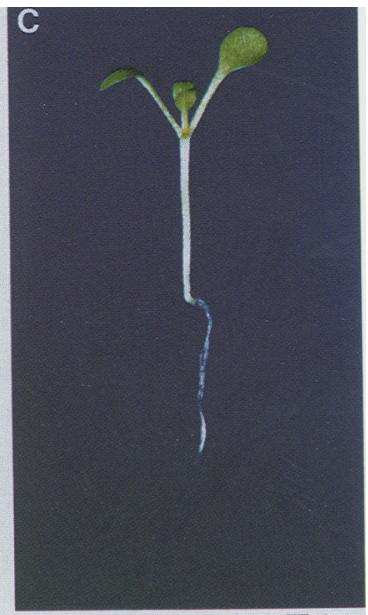

Elevated HAT4 


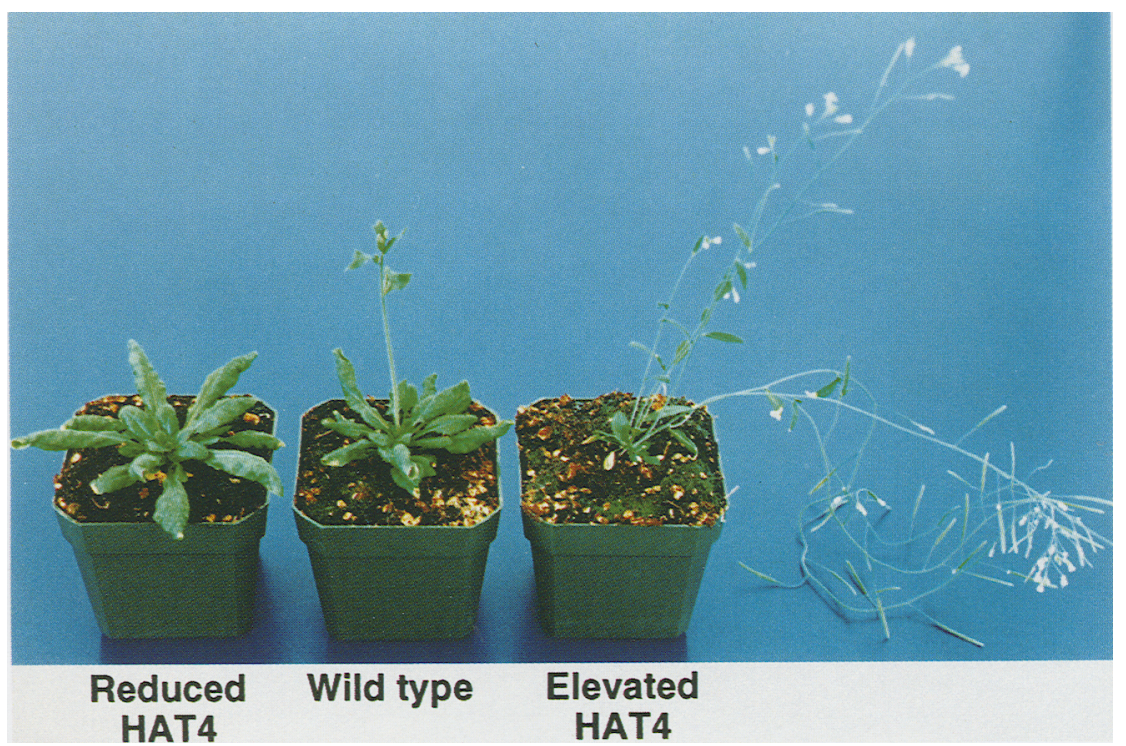

Figure 6. Effect of altered HAT4 expression on adult Arabidopsis development. Seeds were plated on agar and grown under bright light for 7 days. Representative seedlings were then transferred to soil, and grown under bright light for an additional 28 days (see Materials and methods). Photographs of representative plants were taken and correspond to progeny of the following T1 lines (Table 2): (left) 35S-aHAT4 line 1429; (center) 35S-GUS line 1421; and (right) 35S-HAT4 line 1426. Shown below the photograph is the presumptive HAT4 protein level in each plant.
The spacing between the homeo domain and the leucine zipper of HAT4 is identical to the distance between the basic region and the leucine zipper of CCAAT/enhancer-binding protein (C/EBP) (Landschulz et al. 1988), suggesting that HD-Zip and bZIP proteins may recognize DNA in a similar manner. Our initial modeling studies are consistent with the scissors-grip model (Vinson et al. 1989) for DNA recognition, in which leucine zipper-linked HAT4 monomers utilize bifurcated homeo domains to contact successive major grooves (M. Schena and R.W. Davis, unpub.). Of the 12 residues of engrailed that directly contact DNA (Kissinger et al. 1990), 10 are identical or conservatively substituted in HAT4, suggesting that these two proteins may bind to an identical or similar dyad-symmetric DNA sequence. The putative leucine zipper of HAT4 contains, in addition to four heptadic leucines, hydrophobic residues at every fourth position relative to the conserved leucines as would be required for interhelical hydrophobic contacts between monomers (Landschulz et al. 1988; O'Shea et al. 1991). One novel feature of the HAT4 leucine zipper is the presence of three cysteine residues clustered near the first leucine (Leu193) of the zipper, suggesting that HAT4 monomers may form covalent homo- or heterodimers, as has been observed for C/EBP-related proteins (Williams et al. 1991).

Consistent with the developmental role of homeo domain proteins in other organisms (Hayashi and Scott 1990; Lewis 1992), plants with altered HAT4 expression exhibit interesting developmental phenotypes. Plants expressing a HAT4 antisense construct are shorter and develop more slowly than normal, whereas those expressing a HAT4 sense construct are taller and develop more rapidly. One interpretation of these results is that the HAT4 protein normally functions as a master regulator of developmental rate and that reducing or elevating the level of HAT4 slows or accelerates the rate of development, respectively. This proposal would predict that HAT4 should be widely expressed during Arabidopsis development. HAT4 mRNA is detectable in all tissues examined and during all stages of development; moreover, transgenic plants with reciprocal developmental phenotypes have correspondingly elevated or reduced levels of HAT4 mRNA relative to the wild-type

Table 3. Analysis of third-generation (T3) transgenic Arabidopsis lines

\begin{tabular}{lllccc}
\hline $\begin{array}{l}\text { T1 } \\
\text { line }\end{array}$ & Vector & $\begin{array}{l}\text { T2 } \\
\text { line }\end{array}$ & $\begin{array}{l}\text { T3 } \\
\operatorname{Kan}^{\mathrm{R}} / \mathrm{Kan}^{\mathrm{s}}\end{array}$ & $\begin{array}{l}\mathrm{T} 3 \\
\text { hypocotyl (mm) }\end{array}$ & $\begin{array}{l}\text { T3 } \\
\text { phenotype }\end{array}$ \\
\hline 1425 & 35S-HAT4 & $1425-2.1$ & $115: 45$ & $8.1 \pm 0.8$ & tall \\
1426 & 35S-HAT4 & $1426-2.2$ & $106: 38$ & $8.3 \pm 0.6$ & tall \\
1426 & 35S-HAT4 & $1426-2.5$ & $69: 26$ & $8.5 \pm 0.6$ & tall \\
1427 & 35S-HAT4 & $1427-2.1$ & $81: 28$ & $8.7 \pm 0.7$ & tall \\
1427 & 35S-HAT4 & $1427-2.2$ & $118: 43$ & $9.0 \pm 0.8$ & tall \\
1427 & 35S-HAT4 & $1427-2.7$ & $119: 0$ & $8.2 \pm 0.6$ & tall
\end{tabular}

Seeds from self-crossed second generation (T2) Arabidopsis lines were plated, and the third-generation (T3) seedlings were grown and analyzed as described in the Table 2 footnote and in Materials and methods. 


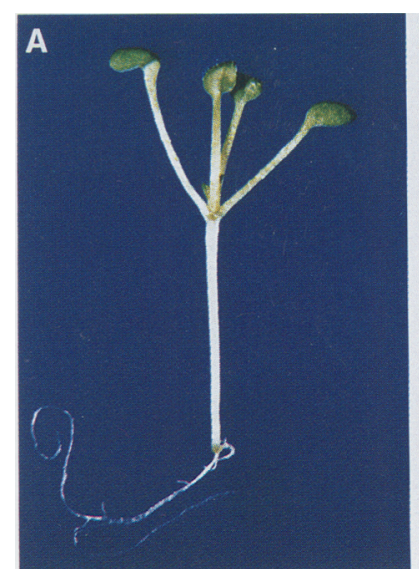

Heterozygous 35S-HAT4

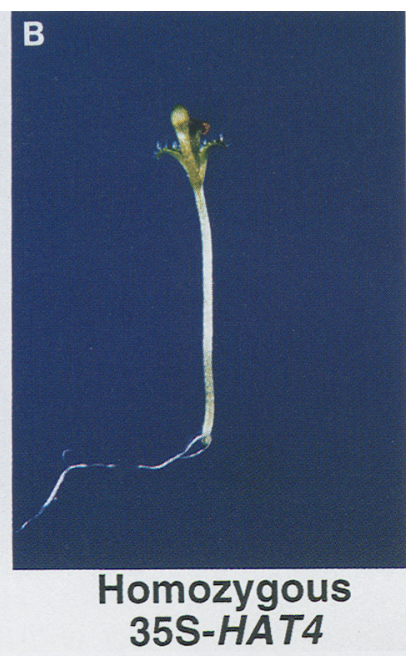

Figure 7. Effect of transgene dosage on seedling development. Seeds were plated on agar and grown for 10 days under bright light (see Materials and methods). Representative seedlings were chosen for the photographs and correspond to progeny of the following T2 lines (Table 3): (A) 35S-HAT4 line 1427-2.2; and $(B)$ 35S-HAT4 line 1427-2.7. Shown below each photograph is the 35S-HAT4 genotype based on the segregation of kanamycin resistance in the T3 lines (Table 3 ).

plants. Although it is not currently possible to measure the levels of the HAT4 protein in the transgenic lines, comparison of homozygous and heterozygous lines derived from the same parent suggests that less than a twofold change in the level of the protein is sufficient to alter development significantly.

An alternative explanation for the developmental changes observed in the transgenic plants is that the phenotypes have nothing to do with normal HAT4 function but, rather, are an indirect consequence of altering the expression of the gene. According to this argument, HAT4 overproduction might induce an alternate pathway such as a stress response in Arabidopsis, which would lead indirectly to developmental changes. Although this explanation is difficult to exclude, several lines of evidence suggest that this model is unlikely. First, except for an increase in developmental rate, plants that overproduce HAT4 fail to exhibit any of the phenotypes normally associated with stress responses such as elevated anthocyanin production, bleaching, necrosis, or reduced fertility. Second, plants harboring an antisense construct exhibit developmental changes that are reciprocal to those seen in plants transformed with a sense construct, suggesting that the physiological role of the gene is to control development. Third, overproduction of other DNA-binding proteins such as steroid receptors, Myc and Myb homologs, and the FLP and Cre recombination factors in plants fails to elicit any of the phenotypes observed when HAT4 expression is altered (M. Schena, A.M. Lloyd, and R.W. Davis, unpubl.).

Plants with altered HAT4 levels undergo morphological changes reminiscent of those that accompany envi-

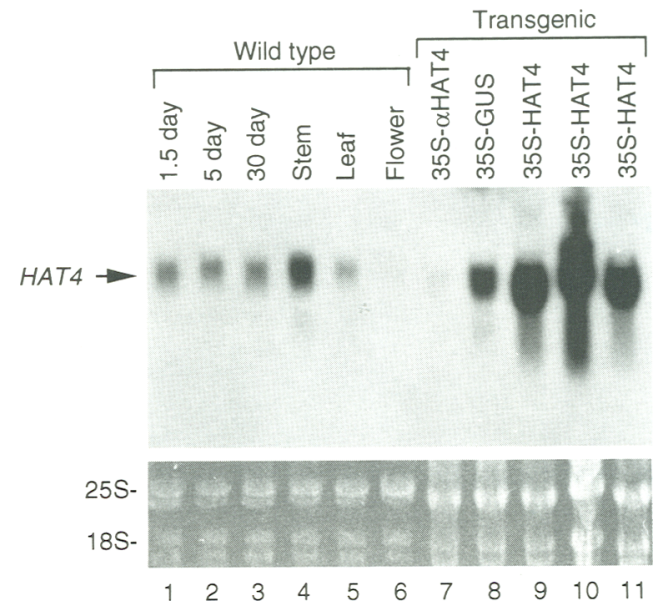

Figure 8. HAT4 expression in wild-type and transgenic plants. Samples of total RNA from wild-type (lanes 1-6) or transgenic (lanes 7-11) plants were fractionated by agarose gel electrophoresis, transferred to a hybridization membrane, and probed with the intact (1.2-kb) HAT4 cDNA (Schena and Davis 1992) radiolabeled by random priming. RNA was isolated from wild-type plants at various times after germination (lanes 1-3), or from various adult (6-week) tissues (lanes 4-6). The transgenic lines (Table 2), propagated under kanamycin selection, are as follows: 35S- $\alpha$ HAT4 line 1429 (lane 7), 35S-GUS line 1421 (lane 8), 35S-HAT4 line 1425 (lane 9), 35S-HAT4 line 1426 (lane 10), and 35S-HAT4 line 1427 (lane 11). The position of the HAT4 transcript is indicated (arrow), as are the positions of the ethidium-stained rRNAs (25S and 18S). Additional experimental details are provided in Materials and methods.

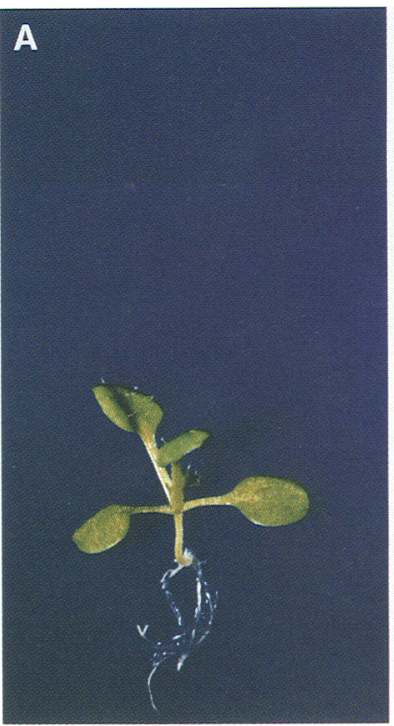

Light

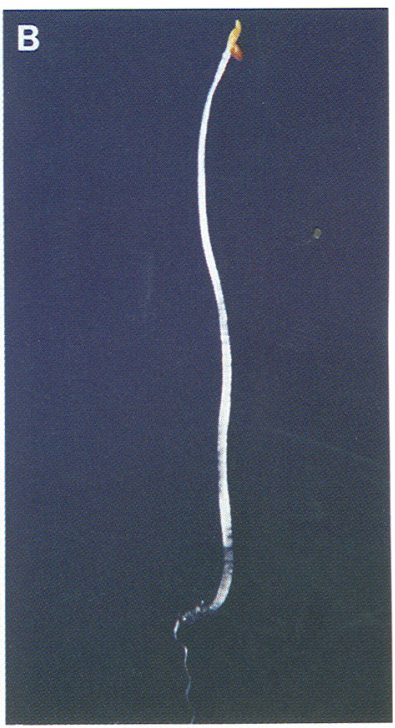

Dark
Figure 9. Effect of light intensity on Arabidopsis seedling development. Seeds were plated on agar and grown for 10 days under either bright light $(A)$ or total darkness $(B)$ (see Materials and methods). Representative seedlings were chosen for the photographs and correspond to progeny of the 35S-GUS T1 line 1421 (Table 2). 


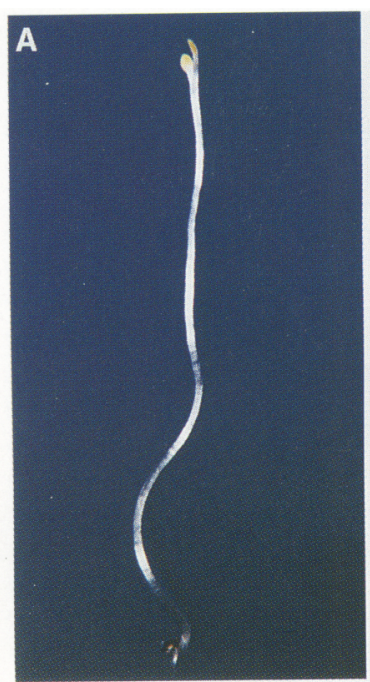

Reduced HAT4

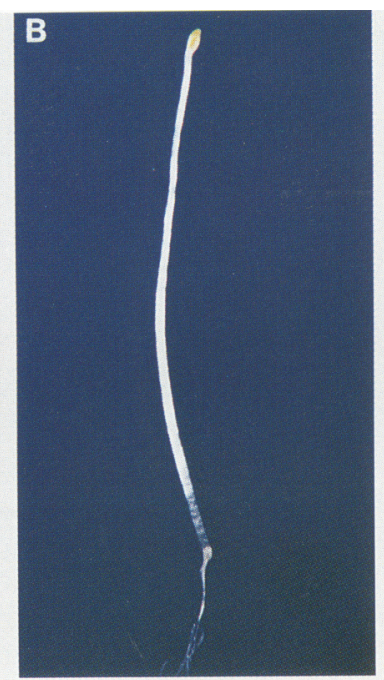

Wild type

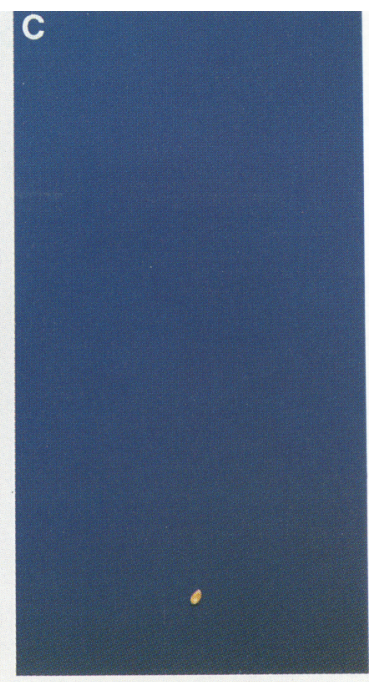

Elevated HAT4
Figure 10. Effect of altered HAT4 expression on germination. Seeds were plated on agar and grown for 10 days in total darkness (see Materials and methods). Representative seedlings were chosen for the photographs and correspond to seeds from the following $\mathrm{T} 1$ lines (Table 2): $(A)$ 35S$\alpha$ HAT4 line $1431 ;(B)$ 35S-GUS line 1421; and $(C)$ 35S-HAT4 line 1425. Given below each photograph is the presumptive HAT4 protein level in each line. ronmental stimuli such as signaling by light (Okada and Shimura 1992) and touch (Braam and Davis 1990). The coupling of growth to the environment in plants is conceptually similar to adaptive responses in other nonmotile organisms such as pseudohyphal growth in Saccharomyces cerevisiae (Gimeno et al. 1992). The etiolation response of higher plants, for example, is analogous to the polarized growth of diploid yeast cells; plants subjected to darkness elongate to reach sunlight, just as yeast cells extend pseudohyphal filaments to forage for a richer nitrogen source (Gimeno et al. 1992; Gimeno and Fink 1992). Sessile organisms such as higher plants and yeast are thus able to respond to nutritional shortages by altering their growth patterns, suggesting that highly sophisticated signaling pathways link the environment to development in plants and fungi. The fact that the HDZip motif has been found in higher plants but not in animals is consistent with the proposal that this motif may be selectively utilized by plants for developmental plasticity (Schena and Davis 1992), a capacity not typically required in animal systems. It may be that homoor heterodimer interactions of $\mathrm{HD}-\mathrm{Zip}$ proteins impart on higher plants the capacity to parlay small fluctuations in environmental conditions into complex and reversible developmental changes.

Overproduction of HAT4 results in a germination defect in the dark, suggesting a possible link between HAT4 and light signaling. Two additional observations are also consistent with the possible cross-talk between light signaling and HAT4 function. First, dark treatment of seeds and HAT4 overproduction have synergistic effects on the plant growth. Second, plants with elevated HAT4 levels are darker green than wild-type plants, suggesting that chlorophyll production has been stimulated. Perhaps plants with elevated levels of HAT4 perceive that the light intensity has been reduced and hence, respond to transgenic elevations of HAT4 by increasing chlorophyll production. Mutants of Arabidopsis with al-

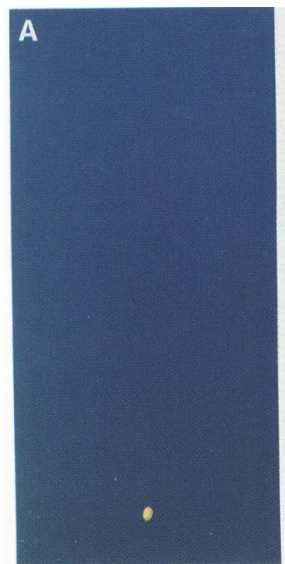

10 Dark

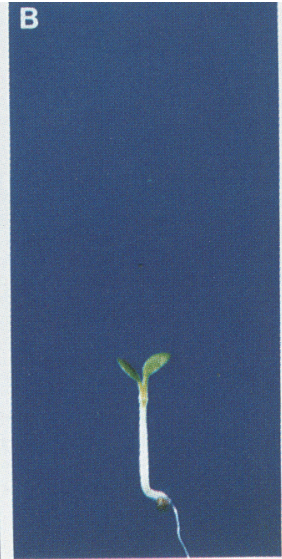

10 Dark + 3 Light

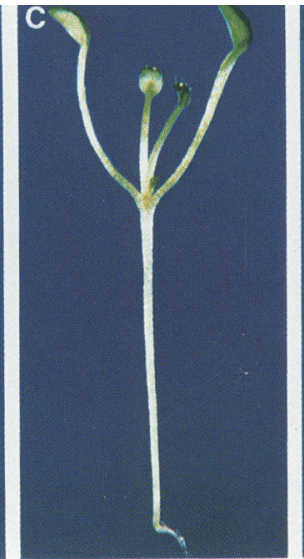

10 Dark + 10 Light

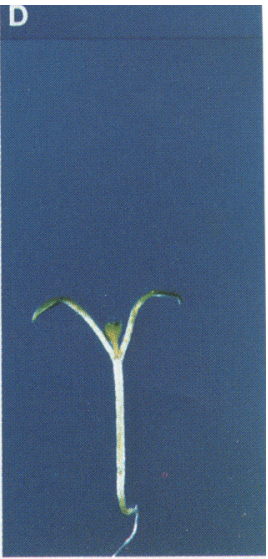

10 Light
Figure 11. Light reversibility of the germination defect. Seeds from the $35 \mathrm{~S}$ HAT4 line 1425 (Table 2) were grown on agar under the following conditions: $(A) 10$ days of total darkness; $(B) 10$ days of total darkness followed by 3 days of bright light; (C) 10 days of total darkness followed by 10 days of bright light; or $(D) 10$ days of bright light (see Materials and methods). Photographs of representative seedlings were taken. The number of days grown in total darkness or bright light is given below each photograph. 
tered growth and light responses/Okada and Shimura 1992) should aid in determining the mechanism of HAT4 action; moreover, the direct isolation of HAT4 target genes using molecular strategies should provide considerable insight into this signaling pathway. Given that both flowering and germination depend on a number of other parameters, including the levels of plant hormones, it will also be interesting to test whether substances such as gibberellins, auxins, or cytokinins are altered in the transgenic lines.

The capacity to accelerate the rate of Arabidopsis development using a single gene suggests possible commercial uses for plant developmental regulatory genes. Overexpression of homeo box genes may provide a general means by which to modify crop plant development. It is interesting to note that overexpression of HAT4 in tobacco leads to phenotypic changes that mimic some of the phenotypes observed in Arabidopsis (M. Schena, A.M. Lloyd, and R.W. Davis, unpubl.). It will be interesting to investigate whether HAT4 or HAT4 homologs exert a similar effect on the development of other commercially important plants, a possibility that can be tested using direct transfer of the HAT4 cDNA or related clones. Given the existence of a large family of homeo box genes, it may ultimately be possible to custom design commercial plants to meet specific agricultural and biotechnological needs.

\section{Materials and methods}

\section{Genomic sequence determination}

Total genomic DNA was isolated (Richards 1988) from Arabidopsis (Columbia) seedlings, purified by cesium chloride ultracentrifugation, and subjected to PCR amplification using primers derived from the sequence of the HAT4 cDNA (Schena and Davis 1992). Five separate reactions containing oligonucleotides PAN17 and PAN31 were prepared and amplified as described (Sambrook et al. 1989). The $1.35-\mathrm{kb}$ reaction products were then cleaved with $X b a I$ and SacI, cloned into Bluescript II $\mathrm{KS}^{+}$(Stratagene), and sequenced using an automated sequencer (Applied Biosystems, Inc).

The sequences of the HAT4 oligonucleotide primers are as follows. PAN 17: 5'-GGGGGGTCTAGACTTATCTTGAGAAAGTTCAA-3' (position 1 in Fig. 1) and PAN31: 5'-GGGGGGGAGCTCCCAAAATGCCCTTTGGTTGC-3' (position 1333 in Fig. 1).

\section{Plasmid constructions}

The yeast expression plasmid pG-LexAGAL4 was constructed by excising the lexAGAL4 sequence from p1027 (Brent and Ptashne 1985) with HindIII, adding BamHI sites to both the $5^{\prime}$ and $3^{\prime}$ ends, and inserting the modified lexAGAL4 fragment into the BamHI site of pG-1 (Schena et al. 1991a). The 5' BamHI site in lexAGAL4, introduced using PCR oligonucleotides PAN22 and PAN23, is located $10 \mathrm{bp}$ upstream of the lexA start codon (Horii et al. 1981). The 3' BamHI site in lexAGAL4 was introduced by end-fill of a HindIII site located $\sim 240$ bp downstream of the GAL4 stop codon (Laughon and Gesteland 1984) and attachment of a synthetic BamHI linker. The junction between lexA (residues 1-87) and GAL4 (residues 74-881) contains a unique XhoI site (Brent and Ptashne 1985). Yeast expres- sion plasmid $\mathrm{pG}$-LexAHAT4GAL4 was made by converting the Xhol site in pG-LexAGAL4 into a SacI site, using PCR oligonucleotides PAN22 and PAN23, and inserting a 390-bp fragment of the HAT4 cDNA (encoding residues 107-237) generated by PCR with PAN24 and PAN20, followed by cleavage with $S a c I$ and $X$ hoI. Plasmid sizes are $\sim 10 \mathrm{~kb}$. [When requesting yeast expression plasmids from the Davis laboratory, please use the following nomenclature: pNN486 (pG-LexAGAL4) and pNN487 (pG-LexAHAT4GAL4).]

The plant expression vectors p35S-HAT4 and p35S- $\alpha$ HAT4 were constructed by excising the $\beta$-glucoronidase (GUS) gene from p35S-GUS (pBI121, Clontech) using $X b a I$ and SacI, and inserting HAT4 cDNA sequences (Schena and Davis 1992) in either the sense (p35S-HAT4) or antisense (p35S- $\alpha$ HAT4) orientation. In p35S-HAT4, the XbaI site was introduced 26 bp upstream of the HAT4 start codon using PCR oligonucleotides PAN17 and PAN18; the SacI site was introduced $\sim 150 \mathrm{bp}$ downstream of the HAT4 translation stop codon by subcloning the cDNA into pUC18, followed by excision with SacI. In p35S$\alpha$ HAT4, the insert is identical to the one present in p35S-HAT4 except that it resides in the opposite orientation; SacI and $\mathrm{XbaI}$ sites were added to HAT4 by subcloning into Bluescript II KS + (Stratagene) and pUC18, followed by excision with SacI and $X b a \mathrm{I}$, respectively. Plasmid sizes are $\sim 13 \mathrm{~kb}$. [When requesting plant expression plasmids from the Davis laboratory, please use the following nomenclature: pNN488 (p35S- $\alpha$ HAT4), pNN489 (p35S-GUS), and pNN490 (p35S-HAT4).]

The sequences of the PCR oligonucleotide primers are as follows. PAN22: 5'-GGGGGGGGATCCAGGGGGCGGAATGAAAGC-3' (upstream of lexA AUG); PAN23: 5'-GCGCGCGAGCTCAGGTTCACCGGCAGCCACACG-3' (lexA codon 87); PAN24: 5'-GGGGGGGAGCTCGAAGAAGACACAGATCCACAA-3' (HAT4 codon 107); PAN20: 5'-GCGCGCCTCGAGGGCACATGGTCAAAGTAG-3' (HAT4 codon 237); PAN18: 5'-CGTTCCATGAAGATCTTCTGA-3' (position 147 in Fig. 1).

\section{PCR mutagenesis}

The 390-bp HAT4 segment of pG-LexAHAT4GAL4 was excised using SacI and XhoI, inserted into Bluescript II KS +, and mutagenized by PCR amplification with T3/T7 or M13forward/ M13 reverse primer pairs. Six $50-\mu l$ reactions containing $10 \mathrm{ng}$ of supercoiled DNA, $50 \mathrm{mM} \mathrm{KCl}, 10 \mathrm{~mm}$ Tris-Cl (pH 8.3), 1.5 $\mathrm{mM} \mathrm{MgCl}_{2}, 0.01 \%$ gelatin, $0.2 \mathrm{mM}$ dNTPs, 50 pmoles of each primer, and 5 units of Taq polymerase (Promega) were overlayed with $100 \mu \mathrm{l}$ of mineral oil and incubated in a thermal cycler (Perkin Elmer Cetus) programmed as follows: 1 cycle, $94^{\circ} \mathrm{C}$ for 5 min; 25 cycles, $94^{\circ} \mathrm{C}$ for $1 \mathrm{~min}, 50^{\circ} \mathrm{C}$ for $2 \mathrm{~min}, 72^{\circ} \mathrm{C}$ for $1 \mathrm{~min}$; 1 cycle, $72^{\circ} \mathrm{C}$ for $10 \mathrm{~min}$. Reaction products were digested with SacI and XhoI, fractionated on low-melt agarose, ligated into SacI/Xhol-linearized pG-LexAHAT4GAL4 vectors, and transformed into $E$. coli by electroporation. Plasmids derived from the three $\mathrm{T} 3 / \mathrm{T} 7$ primer reactions or from the three M13 forward/M13 reverse primer reactions yielded $2 \times 10^{4}$ bacterial transformants ( $\mathrm{T}$ pool) and $3 \times 10^{4}$ transformants ( $\mathrm{M}$ pool), respectively. Plasmid DNA from the $T$ pool and $M$ pool transformants was purified using Qiagen columns as recommended by the manufacturer.

\section{Yeast slow growth reversal assay}

Competent cells of yeast strain BJ2168 (MATa, pep4-3, prc1407, prb1-1122, ura3-52, trp1, leu2), grown using standard media (Sherman 1991), were prepared using the lithium acetate procedure (Ito et al. 1983) except that the carrier DNA was denatured to increase the transformation efficiency (Schiestl 
and Gietz 1989). Aliquots of the mutagenized pG-LexAHAT4GAL4 plasmid pools ( $T$ and $M$ ) were cotransformed with a

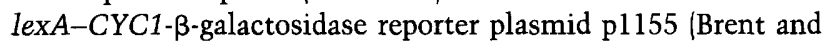
Ptashne 1985) into competent BJ2168 cells and plated on minimal agar lacking uracil and tryptophan at a density of 250 transformants per $10-\mathrm{cm}$ plate. A total of 5000 transformants yielded 26 colonies that exhibited a slow growth reversal $/ \beta$-gal ${ }^{+}$phenotype. DNA from 13 of the 26 yeast clones was isolated (Schena et al. 1989), and pG-LexAHAT4GAL4 plasmids were recovered by transformation into $E$. coli. Inserts from each of the 13 plasmids were liberated by digestion with XhoI and SacI, inserted into Bluescript II $\mathrm{KS}+$, and sequenced using an automated sequencer. The inserts derived from the $\mathrm{T}$ pool $\langle\mathrm{T} 3,4,6$, $15,28,51,52,72)$ and the $M$ pool $(M 7,14,15,25,78)$ were then reintroduced into pG-LexAHAT4GAL4 lacking the HAT4 sequence and transformed into yeast strain BJ2168, and $\beta$-gal assays were performed using at least three independent transformants (Yocum et al. 1984).

\section{Arabidopsis transformation}

Expression plasmids p35S-aHAT4, p35S-GUS and p35S-HAT4 were introduced into Agrobacterium tumefaciens strain LBA4404 (Clontech) by electroporation (Nagel et al. 1990). Arabidopsis lines (Col-O or RLD-O) were then transformed by Agrobacterium-mediated root transformation (Valvekens et al. 1988) and regenerated in the presence of kanamycin to select for stable integration of the expression plasmids. Regenerants were moved to soil $\sim 8$ weeks after transformation, and seed from 18 independent lines was collected $\sim 4$ weeks later.

\section{Arabidopsis growth and phenotypic analysis}

Seeds were surface sterilized (two treatments for $10 \mathrm{~min}$ with $20 \%$ bleach, $0.05 \%$ Triton X-100) and plated aseptically in 10 $\mathrm{cm} \times 2.5-\mathrm{cm}$ petri dishes (Nunc) containing $25 \mathrm{ml}$ of agar $(\mathrm{pH}$ 5.8 ) consisting of $1 \times$ MS salts (GIBCO), $0.7 \%$ Bacto-agar, $2 \%$ sucrose, $1 \times$ vitamins $(1.3 \mu \mathrm{g} / \mathrm{ml}$ of nicotinic acid, $0.25 \mu \mathrm{g} / \mathrm{ml}$ of thiamine, $1.0 \mu \mathrm{g} / \mathrm{ml}$ of pyridoxine, and $0.25 \mu \mathrm{g} / \mathrm{ml}$ of pantothenic acid), and $50 \mu \mathrm{g} / \mathrm{ml}$ of kanamycin. Dishes were sealed with parafilm, incubated in growth chambers at $22^{\circ} \mathrm{C}$ under continuous bright light $\left(3.2 \times 10^{3} \mathrm{lux}\right)$, and scored for kanamycin resistance or hypocotyl length after 10 days. Photographs of representative 10-day-old kanamycin resistant seedlings were taken using Ultra 50 color film (Agfa) in a Zeiss Stemi SV6 photomicroscope set at eightfold magnification. Dark experiments were performed exactly as described above except that dishes containing sterile seeds were wrapped in a double layer of aluminum foil and incubated in a dark growth chamber. DNA was isolated from $\mathrm{T} 2$ seedlings derived from each of the T1 lines and assayed for the presence of a given expression vector using the PCR oligonucleotide PAN36, together with PAN19 (35S$\alpha$ HAT4), PAN37 (35S-GUS), or PAN20 (35S-HAT4).

After 7 days of growth on kanamycin plates, seedlings were transferred from petri dishes to $2.5-\mathrm{cm}$ pots containing Sunshine Mix potting soil (Fisons Horticulture, Inc.). Plants were grown under continuous bright light $\left(4.8 \times 10^{3} \mathrm{lux}\right)$ at $24^{\circ} \mathrm{C}$, watered regularly using Peters $20-20-20$ soluble plant food (Grace-Sierra Horticultural Products Company) at $200 \mathrm{mg} / \mathrm{liter}$, and scored for the formation of siliques by visual inspection. Photographs of representative 28-day-old plants were taken using an Olympus OM-2 camera equipped with a $50-\mathrm{mm}$ Zuiko lens and Ultra 50 color film (Agfa).

The sequences of the PCR oligonucleotide primers are as follows: PAN36: 5'-GATGTGATATCTCCACTGAC-3' (35S promoter); PAN19: 5'-GGGGGGCTCGAGAAGAAGACACAGA-
TCCA-3' (HAT4 antisense); and PAN37: 5'-ACGCTGCGATGGATCCCGGC-3' (GUS gene).

\section{RNA analysis}

Total RNA was isolated and analyzed as described previously (Schena and Davis 1992), with certain modifications. Pulverized tissue was homogenized in a buffer containing equal volumes of phenol/chloroform/isoamyl alcohol [50:50:1 (vol/vol)] and yeast RNA extraction buffer ( $150 \mathrm{~mm} \mathrm{NaCl}, 5 \mathrm{~mm}$ EDTA, $4 \%$ SDS, $50 \mathrm{~mm}$ Tris- $\mathrm{Cl}$ at $\mathrm{pH} 7.5$ ) and precipitated with ethanol. The RNA was resuspended in TE buffer and subjected to two additional rounds of phenol extraction and ethanol precipitation.

\section{Acknowledgments}

We thank Michael Campbell, Anna Astromoff, Matt Scott, and Grace Yen for critical comments on the manuscript, and Daphne Preuss, Chris Lee, and Keith Yamamoto for helpful insights. We also thank members of the PAN Facility at Stanford University for oligonucleotide synthesis and DNA sequencing. This work was supported by grants from the National Science Foundation (DMR-91060-11) and the National Institutes of Health (8 R37 HG00198-17) to R.W.D.; M.S. holds a National Science Foundation Postdoctoral Fellowship in Plant Biology.

The publication costs of this article were defrayed in part by payment of page charges. This article must therefore be hereby marked "advertisement" in accordance with 18 USC section 1734 solely to indicate this fact.

\section{References}

Berger, S.L., B. Piña, N. Silverman, G.A. Marcus, J. Agapite, J.L. Regier, S.J. Triezenberg, and L. Guarente. 1992. Genetic isolation of $\mathrm{ADA} 2$ : A potential transcriptional adaptor required for function of certain acidic activation domains. Cell 70: 251-265.

Braam, J. and R.W. Davis. 1990. Rain-, wind-, and touch-induced expression of calmodulin and calmodulin-related genes in Arabidopsis. Cell 60: 357-364.

Brent R. and M. Ptashne. 1985. A eukaryotic transcriptional activator bearing the DNA specificity of a prokaryotic repressor. Cell 43: 729-736.

Davis, R.L., H. Weintraub, and A.B. Lassar. 1987. Expression of a single transfected cDNA converts fibroblasts to myoblasts. Cell 51: 987-1000.

Dorit, R.L., L. Schoenbach, and W. Gilbert. 1990. How big is the universe of exons? Science 250: 1377-1382.

Gehring, W.J. 1987. Homeo boxes in the study of development. Science 236: 1245-1252.

Gehring, W.J., M. Müller, M. Affolter, A. Percival-Smith, M. Billeter, Y.Q. Qian, G. Otting, and K. Wüthrich. 1990. The structure of the homeodomain and its functional implications. Trends Genet. 6: 323-329.

Gill, G. and M. Ptashne. 1988. Negative effect of the transcriptional activator GAL4. Nature 334: 721-724.

Gimeno, C.J., and G.R. Fink. 1992. The logic of cell division in the life cycle of yeast. Science 257: 626 .

Gimeno, C.J., P.O. Ljungdahl, C.A. Styles, and G.R. Fink. 1992. Unipolar cell divisions in the yeast $S$. cerevisiae lead to filamentous growth: Regulation by starvation and RAS. Cell 68: $1077-1090$.

Guarente, L. and O. Bermingham-McDonogh. 1992. Conservation and evolution of transcriptional mechanisms in eukary- 
otes. Trends. Genet. 8: 27-32.

Hayashi, S. and M.P. Scott. 1990. What determines the specificity of action of Drosophila homeodomain proteins? Cell 63: $883-894$.

Horii, T., T. Ogawa, and H. Ogawa. 1981. Nucleotide sequence of the $\operatorname{lex} A$ gene of E. coli. Cell 23: 689-697.

Hu, J.C., E.K. O'Shea, P.S. Kim, and R.T. Sauer. 1990. Sequence requirements for coiled-coils: Analysis with $\lambda$ repressorGCN4 leucine zipper fusions. Science 250: 1400-1403.

Ito, H., Y. Fukuda, K. Murata, and A. Kimura. 1983. Transformation of intact yeast cells treated with alkali cations. $J$. Bacteriol. 53: 163-168.

Katagiri, F. and N.-H. Chua. 1992. Plant transcription factors: Present knowledge and future challenges. Trends. Genet. 8: 22-27.

Kaufman, T.C., M.A. Seeger, and G. Olsen. 1990. Molecular and genetic organization of the antennapedia gene complex of Drosophila melanogaster. Adv. Genet. 27: 309-362.

Kissinger, C.R., B. Liu, E. Martin-Blanco, T.B. Kornberg, and C.O. Pabo. 1990. Crystal structure of an engrailed homeodomain-DNA complex at 2.8 å resolution: A framework for understanding homeodomain-DNA interactions. Cell 63: 579-590.

Koornneef, M. 1981. The complex syndrome of $t \mathrm{tg}$ mutants. Arabidopsis Inf. Serv. 18: 45-51.

Landschulz, W.H., P.F. Johnson, and S.L. McKnight. 1988. The leucine zipper: A hypothetical structure common to a new class of DNA binding proteins. Science 240: 1759-1764.

Laughon, A. and R.F. Gesteland. 1984. Primary structure of the Saccharomyces cerevisiae GAL4 gene. Mol. Cell. Biol. 4: 260-267.

Lewis, E.B. 1992. Clusters of master control genes regulate the development of higher organisms. I. Am. Med. Assoc. 267: 1524-1531.

Lloyd, A.M., V. Walbot, and R.W. Davis. 1992. Arabidopsis and Nicotiana anthocyanin production activated by maize regulators $R$ and C1. Science 258: 1773-1775.

Ludwig, S.R., L.F. Habera, S.L. Dellaporta, and S.R. Wessler. 1989. Lc, a member of the maize $R$ gene family responsible for tissue-specific anthocyanin production, encodes a protein similar to transcriptional activators and contains the myc-homology region. Proc. Natl. Acad. Sci. 86: 7092-7096.

Ma, J., E. Przibilla, J. Hu, L. Bogorad, and M. Ptashne. 1988. Yeast activators stimulate plant gene expression. Nature 334: 631-633.

Ma, H., M.F. Yanofsky, and E.M. Meyerowitz. 1991. AGL1$A G L 6$, an Arabidopsis gene family with similarity to floral homeotic and transcription factor genes. Genes \& Dev. 5: 484-495.

Mattsson, J., E. Söderman, M. Svenson, C. Borkird, and P. Engström. 1992. A new homeobox-leucine zipper gene from $A r$ abidopsis thaliana. Plant Mol. Biol. 18: 1019-1022.

McGinnis, W. and R. Krumlauf. 1992. Homeobox genes and axial patterning. Cell 68: 283-302.

Mitchell, P.J. and R. Tjian. 1989. Transcriptional regulation in mammalian cells by sequence-specific DNA binding proteins. Science 245: 371-378.

Nagel, R., A. Elliot, A. Masel, R.G. Birch, and J.M. Manners. 1990. Electroporation of binary Ti plasmid vector into Agrobacterium tumefaciens and Agrobacterium rhizogenes. FEMS Microbiol. Lett. 67: 325-328.

Nambu, J.R., J.O. Lewis, K.A. Wharton, Jr., and S.T. Crews. 1991. The Drosophila single-minded gene encodes a helixloop-helix protein that acts as a master regulator of CNS midline development. Cell 67: 1157-1167.

Okada, K. and Y. Shimura. 1992. Aspects of recent develop- ments in mutational studies of plant signaling pathways. Cell 70: 369-372.

Oppenheimer, D.G., P.L. Herman, S. Sivakumaran, J. Esch, and M.D. Marks. 1991. A myb gene required for leaf trichome differentiation in Arabidopsis is expressed in stipules. Cell 67: 483-493.

O'Shea, E.K., R. Rutkowski, and P.S. Kim. 1989. Evidence that the leucine zipper is a coiled coil. Science 243: 538-542.

O'Shea, E.K., J.D. Klemm, P.S. Kim, and T. Alber. 1991. X-ray structure of the GCN4 leucine zipper, a two-stranded, parallel coiled coil. Science 254: 539-544.

Ptashne, M. and A.A.F. Gann. 1990. Activators and targets. Nature 346: 329-331.

Richards, E. 1988. Preparation of genomic DNA from plant tissue. In Current protocols in molecular biology led. F.M. Ausubel, R. Brent, R.E. Kingston, D.D. Moore, and J.A. Smith|, pp. 2.3.1-3. Greene/Wiley-Interscience, New York.

Ruberti, I., G. Sessa, S. Lucchetti, and G. Morelli. 1991. A novel class of plant proteins containing a homeodomain with a closely linked leucine zipper motif. EMBO /. 10: 1787-1791.

Sambrook, I., E.F. Fritsch, and T. Maniatis. 1989. Molecular cloning: A laboratory manual. Cold Spring Harbor Laboratory Press, Cold Spring Harbor, New York.

Schena, M. 1989. The evolutionary conservation of eukaryotic gene transcription. Experientia 45: 972-983.

Schena, M. 1990. "Mammalian glucocorticoid receptor action in yeast." Ph.D. thesis, University of California at San Francisco, San Francisco, CA.

Schena, M. and R.W. Davis. 1992. HD-Zip proteins: Members of an Arabidopsis homeodomain protein superfamily. Proc. Natl. Acad. Sci. 89: 3894-3898.

Schena, M. and K.R. Yamamoto. 1988. Mammalian glucocorticoid receptor derivatives enhance transcription in yeast. Science 241: 965-967.

Schena, M., L.P. Freedman, and K.R. Yamamoto. 1989. Mutations in the glucocorticoid receptor zinc finger region that distinguish interdigitated DNA binding and transcriptional enhancement activities. Genes \& Dev. 3: 1590-1601.

Schena, M., D. Picard, and K.R. Yamamoto. 1991a. Vectors for constitutive and inducible gene expression in yeast. Methods Enzymol. 194: 389-398.

Schena, M., A.M. Lloyd, and R.W. Davis. 1991b. A steroid-inducible gene expression system for plant cells. Proc. Natl. Acad. Sci. 88: 10421-10425.

Schiestl, R.H. and R.D. Gietz. 1989. High efficiency transformation of intact yeast cells using single stranded nucleic acids as a carrier. Curr. Genet. 16: 339-346.

Scott, M.P., J.W. Tamkun, and G.W. Hartzell, III. 1989. The structure and function of the homeodomain. Biochim. Biophys. Acta 989: 25-48.

Sherman, F. 1991. Getting started with yeast. Methods Enzymol. 194: 3-21.

Struhl, K. 1989. Helix-turn-helix, zinc-finger, and leucine-zipper motifs for eukaryotic transcriptional regulatory proteins. Trend. Biochem. Sci. 14: 137-140.

Valvekens, D., M. Van Montagu, and M. Van Lijsebettens. 1988. Agrobacterium tumefaciens-mediated transformation of $A r$ abidopsis thaliana root explants by using kanamycin selection. Proc. Natl. Acad. Sci. 85: 5536-5540.

Vinson, C.R., P.B. Sigler, and S.L. McKnight. 1989. Scissors-grip model for DNA recognition by a family of leucine zipper proteins. Science 246: 911-916.

Vollbrecht, E., B. Veit, N. Sinha, and S. Hake. 1991. The developmental gene Knotted-1 is a member of a maize homeobox gene family. Nature 350: 241-243.

Weintraub, H., R. Davis, S. Tapscott, M. Thayer, M. Krause, R. 
Benezra, T.K. Blackwell, D. Turner, R. Rupp, S. Hollenberg, Y. Zhuang, and A. Lassar. 1991. The myoD gene family: Nodal point during specification of the muscle cell lineage. Science 251: 761-766.

Williams, S.C., C.A. Cantwell, and P.F. Johnson. 1991. A family of C/EBP-related proteins capable of forming covalently linked leucine zipper dimers in vitro. Genes \& Dev. 5: 15531567.

Wilson, T.E., T.J. Fahrner, M. Johnston, and J. Milbrandt. 1991. Identification of the DNA binding site for NGFI-B by genetic selection in yeast. Science 252: 1296-1300.

Wolberger, C., A.K. Vershon, B. Liu, A.D. Johnson, and C.O Pabo. 1991. Crystal structure of a MAT $\alpha 2$ homeodomainoperator complex suggests a general model for homeodomain-DNA interactions. Cell 67: 517-528.

Yanofsky, M.F., H. Ma, J.L. Bowman, G.N. Drews, K.A. Feldmann, and E.M. Meyerowitz. 1990. The protein encoded by the Arabidopsis homeotic gene agamous resembles transcription factors. Nature 346: 35-39.

Yocum, R.R., S. Hanley, R. West, Jr., and M. Ptashne. 1984. Use of lacZ fusions to delimit regulatory elements of the inducible divergent GALl-GAL10 promoter in Saccharomyces cerevisiae. Mol. Cell. Biol. 4: 1985-1998. 


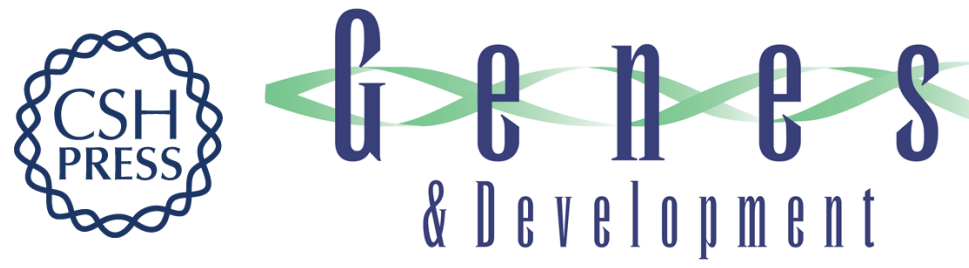

\section{The HAT4 gene of Arabidopsis encodes a developmental regulator.}

M Schena, A M Lloyd and R W Davis

Genes Dev. 1993, 7:

Access the most recent version at doi:10.1101/gad.7.3.367

References This article cites 56 articles, 22 of which can be accessed free at: http://genesdev.cshlp.org/content/7/3/367.full.html\#ref-list-1

License

Email Alerting Service

Receive free email alerts when new articles cite this article - sign up in the box at the top right corner of the article or click here.

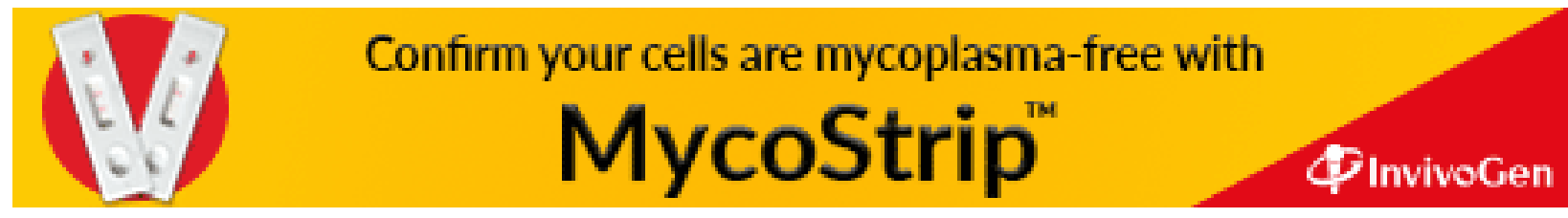

